\title{
Los Derechos Humanos se conquistan en la lucha: igualdad racial, activismo jurídico y la defensa de las causas colectivas en el sur de Brasil ${ }^{1}$
}

\author{
FERNANDA RÍOS PETRARCA
}

\section{Resumen}

Este artículo analiza la relación entre la defensa de causas colectivas vinculadas con la cuestión racial y la actuación profesional basada en una expertise jurídica en el sur de Brasil. Se centra en un conjunto de abogados que actúan profesionalmente en defensa de la igualdad racial en el estado de Rio Grande do Sul. A partir de este recorte empírico se examina tanto la emergencia del derecho racial en Brasil como el surgimiento de abogados que defienden "causas raciales". Se analizan además las diferentes modalidades de asociación entre intervención profesional y compromiso militante a partir de la investigación de las trayectorias sociales, políticas y militantes de los abogados. Los procedimientos metodológicos adoptados consistieron en entrevistas biográficas con "profesionales militantes" y el análisis de fuentes secundarias referidas a los entrevistados. Este estudio permitió mostrar que los principios de identificación étnico-racial y el compromiso militante son fundamentales para conformar determinadas concepciones y prácticas profesionales.

PALABRAS CLAVE: Derechos humanos; igualdad racial; activismo jurídico; actuación profesional; compromiso militante, Brasil.

\begin{abstract}
This article analyzes the relation between the defense of collective causes related to race and professional performance based on expertise and legal knowledge in southern Brazil. It focuses on a group of lawyers who act professionally in defense of racial equality in Rio Grande do Sul. The article examines the emergence of racial rights in Brazil and lawyers who defend "racial causes". Moreover, the article analyzes the different modalities of association between professional intervention and militant commitment, by examining the lawyers' social and political trajectories. The methodology consisted of biographical interviews with "militant professionals" and analysis of secondary sources. This study demonstrates that ethnic-racial identity and political commitment are fundamental elements in the formation of professional conceptions.
\end{abstract}

KEYWORDS: Human Rights, racial equality, judicial activism, professional intervention, militant commitment, Brazil. 
$\mathrm{E}$ análisis realizado forma parte de una investigación más amplia sobre las modalidades de asociación entre diferentes saberes profesionales y expertos y la defensa de "causas raciales" ${ }^{2}$. Tal investigación involucró fundamentalmente dos dimensiones. La primera comprendió el análisis del rol y de la importancia de la formación académica para la ocupación de cargos en movimientos sociales y en grupos volcados a la defensa de la cuestión racial. Sobre esta base, la investigación priorizó -a partir de las trayectorias y de los itinerarios sociales, políticos y profesionales de los agentes- destacar de qué forma diferentes actividades profesionales y formaciones académicas (periodismo, psicología, derecho, medicina, enfermería) asumen actualmente un papel esencial en el reclutamiento y selección de nuevos cuadros y elites militantes, contribuyendo hacia nuevas modalidades de usos del título y de la profesión. La segunda dimensión implicó el análisis de las formas concretas de compromiso en la defensa de las "causas raciales", con el fin de aprehender y comprender las concepciones y los sentidos atribuidos a la formación profesional y a la actuación militante.

Tomando como referencia esta investigación más amplia y las dimensiones anteriormente planteadas, este artículo se centra en un conjunto de abogados que actúan en la defensa de movimientos sociales, grupos y personas en pro de la igualdad racial. El objetivo principal del presente texto consiste en indagar, a partir del análisis de los agentes que se dedican a traducir el universo jurídico a los movimientos sociales, la relación entre el saber jurídico y la defensa de la igualdad racial. Para dar cuenta de tal objetivo, este artículo está dividido en cuatro partes. En una primera parte se busca mostrar cómo la relación entre profesión, conocimiento experto y compromiso militante deviene un importante objeto de las ciencias sociales. En la segunda parte el artículo discute el surgimiento de nuevos derechos y la emergencia del activismo jurídico así como el conjunto de problemas destacados por la literatura especializada para el análisis de esta cuestión. Por lo tanto, se trata de mostrar cómo se constituyeron el espacio actual de las posiciones profesionales posibles de ser ocupadas en el derecho, la profesionalización del activismo jurídico y el surgimiento de nuevas competencias técnicas y profesionales relacionadas con la actuación en defensa de los movimientos sociales. Una de las cuestiones principales que se evidencian es que la emergencia del activismo jurídico está asociada a la diversificación del campo profesional y a la actuación simultánea de los profesionales en varios espacios, como el de la abogacía y el de la militancia. En la tercera parte se analiza la emergencia del derecho racial y la organización de los abogados en defensa de las víctimas de discriminación racial en Brasil. Entre varios de los ejemplos que pueden ser citados referidos a "causas raciales", está el de la "Associação Brasileira de Advogados Afro-descendentes", el del "Instituto do

2 Esta investigación forma parte del proyecto de posdoctorado que realiza actualmente la autora en la Universidad Federal de Rio Grande do Sul y que cuenta con financiación del Conselho Nacional de Desenvolvimento Científico e Tecnológico (CNPq). 
Advocacia Racial y Ambiental" y el Proyecto "sos Racismo", implementado por organizaciones no gubernamentales con el apoyo del gobierno federal. El principal objetivo de este apartado consiste en mostrar las concepciones asociadas al papel del derecho en la defensa de las víctimas de discriminación racial. En la cuarta y última parte pretendo discutir los problemas referentes a las modalidades de asociación entre actuación profesional y defensa de causas colectivas en el caso específico de las "causas raciales" en Rio Grande do Sul. Esto implica mostrar de qué forma el activismo jurídico se convierte en un recurso para la movilización en defensa de ciertas causas y cuál es su relación con las trayectorias e itinerarios de los agentes que intervienen en ellas. Se trata de profesionales que actúan en espacios simultáneos y que articulan el compromiso político con el ejercicio profesional del derecho. Por lo tanto, a partir del análisis de las actuaciones concretas y de las trayectorias de algunos abogados que ocupan posiciones en entidades y movimientos sociales volcados a la cuestión racial en Rio Grande do Sul, se pretende discutir el problema de la relación entre compromiso militante, identidades raciales y actuación profesional.

\section{La relación entre profesión y militancia: un objeto para las ciencias sociales}

El análisis de la relación entre militancia y ejercicio profesional presenta un conjunto de desafíos teóricos y metodológicos. Uno de los problemas destacados por la literatura reciente, y que interesa a este texto particularmente, se refiere a los procesos de reconversión profesional de la actividad militante. El análisis de la relación entre estos dos universos sociales constituye un objeto nuevo para las ciencias sociales. La bibliografía enfatizó, durante mucho tiempo, la organización y la dinámica interna de estos espacios sin establecer un diálogo entre ellos. Por un lado se destaca un vasto conjunto de trabajos orientados al estudio de los procesos de compromiso y movilización colectiva, los cuales formaron parte de las discusiones de la sociología de los movimientos sociales y la acción colectiva. Por otro lado, predominaron los estudios sobre la formación de grupos profesionales y su dinámica interna de organización y funcionamiento, que se insertaron en las discusiones de la llamada "sociología de las profesiones". Sólo recientemente la relación entre "profesión", "política" y "militancia" se ha convertido en objeto de un conjunto de estudios e investigaciones.

La literatura actual ha resaltado tanto la profesionalización de la militancia y de la política como las retribuciones de la actuación militante y las reconversiones de las competencias profesionales (Offerlé, 1996, 1999; Sawicki, 1999). Uno de los aspectos recurrentes en estos trabajos ha sido la confrontación entre los enfoques que se centran en las "afinidades" entre determinadas profesiones y la política, planteando una especie de "ósmosis" o "vivier" entre ambas (Weber, 1982, Dogan, 1999) y los que se han preocupado por las diversas modalidades de 
uso de las cualificaciones y relaciones profesionales en las también diversificadas formas de actuación e inserción en la política (Willemez, 1999, Coradini, 2001, Dulong, 1996). Los trabajos de Dogan (1999), por ejemplo, destacan la permeabilidad, la proximidad social y las afinidades entre el ejercicio de determinadas profesiones y la política como una especie de continuidad que se encuentra, sobre todo, en las profesiones que exigen un dominio de la oratoria y de la práctica discursiva. Éste es el caso del magisterio, de la abogacía y del periodismo. Otro conjunto de investigaciones se ha interesado en las diversas relaciones posibles entre el ejercicio profesional y la actuación política. Este es el caso del estudio de Dulong (1996) que demuestra cómo ciertas competencias profesionales -en su caso aquellas adquiridas en el ejercicio de la economía- se pueden convertir en competencias políticas.

De modo semejante, las investigaciones de Gaxie (2005) y Gaxie y Offerlé (1985) se han centrado en las diversas retribuciones y recompensas que el militantismo y la acción colectiva proporcionan, demostrando que la experiencia militante y el compromiso hacia organizaciones colectivas ofrecen ganancias y lucros, facilitando, inclusive, la inserción en el mercado de trabajo. Los trabajos de Coradini $(2001,2006)$ también han proporcionado contribuciones relevantes para entender cómo el ejercicio profesional y la actuación en asociaciones y sindicatos profesionales se convierten en modalidades de ingreso a la política y de creación de trayectorias vinculadas a la misma. El autor destaca la relación entre actuación profesional y la representación de intereses basados en la condición profesional y su conversión en representación política.

Tales investigaciones, al mostrar la imbricación entre estas esferas, proporcionaron un conjunto de problemas e interrogantes a ser analizados, permitiendo repensar el tratamiento dado hasta entonces a las profesiones, a la movilización social y a la acción colectiva. De este modo, esta literatura permite demostrar que las modalidades de uso de los títulos escolares en la esfera política y militante dependen tanto de la afinidad y de la proximidad social que existe entre ciertas profesiones y el desarrollo de un trabajo de movilización política como de la posición ocupada por el agente al interior del espacio académico y profesional y del conjunto de recursos sociales que es capaz de movilizar (Bourdieu, 1975). En este sentido, el compromiso en causas colectivas puede consistir en una forma de reconvertir inserciones académicas y profesionales en triunfos político-militantes, como también en una forma de transformar vínculos militantes en éxitos profesionales.

Así, las condiciones de asociación entre títulos escolares, profesionales y capital militante se vuelven un foco de atención para el análisis de las diferentes lógicas sociales (profesional y política) en juego. Lo que plantea dos cuestiones principales: la reconversión de las competencias profesionales y las retribuciones de la actuación política (Coradini, 2001, 2002, 2006; Offerlé, 1996, 1999). En esta línea se ha planteado un conjunto de problemas tales como: a) en qué medida la propia formación universitaria y el ejercicio de la profesión se pueden convertir en un recurso importante para actuar en la esfera de la política y de la 
militancia; b) cómo el ejercicio de la militancia y la participación política pueden constituirse en un recurso en las disputas por cargos y posiciones dentro del espacio profesional.

De este modo, la posibilidad de ocupar posiciones en otras esferas sociales, además de la esfera profesional, depende no sólo del título académico sino de la posición social del agente y de la acumulación de varios recursos sociales. La actuación profesional en espacios de movilización colectiva se ha presentado tanto como una forma de diversificar las posibilidades de actuación profesional como una forma singular de recorrer el espacio de la política, ya que permite relacionar la formación y la profesión con el compromiso y la participación política, contribuyendo así a ampliar el capital militante y generando las condiciones para su conversión en capital político y profesional. El fenómeno de la "militancia profesional", tal como ha sido definido por la literatura especializada, se convierte en un importante instrumento de socialización política y de inserción en el espacio político (Matonti y Poupeau, 2004).

Sin embargo, los títulos escolares no constituyen solamente un simple incremento en los atributos profesionales de los militantes. Lo que se destaca son las modalidades de relacionar la formación especializada y la profesión con la militancia en diferentes esferas sociales. En este sentido, este trabajo busca dar cuenta de las formas diversificadas de relacionar y articular el conocimiento especializado, la profesión y la actuación política en movimientos sociales dedicados a la defensa de causas colectivas diversas y las posibles conversiones en juego. Es decir, los recursos obtenidos en otras esferas de actuación pueden ser transferidos hacia la militancia.

En Brasil se ha observado una fuerte imbricación entre formación universitaria y esfera política. Gran parte de la literatura nacional sobre este tema ha abordado la importancia que la esfera política asume en la ampliación de las posibilidades de intervención profesional y en los usos de la formación universitaria. Esta imbricación se manifiesta en diversas profesiones como forma de valorización de los títulos académicos y de estructuración de los universos profesionales (Bonelli, 1999, 2003; Coradini, 1997; Loureiro, 1997). En este sentido, el análisis de la relación entre profesión y politica debe considerar la manera en que se configuran estas esferas sociales y los recursos políticos y profesionales asociados a ellas en situaciones históricas particulares. Esto permite comprender mejor los universos profesionales y las concepciones que están en juego sobre la profesión.

En función de lo anterior, uno de los problemas considerados por la literatura ha sido la relación entre las esferas de actuación en las cuales están insertos los militantes y los recursos sociales acumulados y accionados en estos compromisos en diferentes esferas. Esta relación permite analizar las formas y los procesos de identificación y las representaciones producidas sobre el universo profesional en tanto las identidades son instituidas a través de la inserción de los individuos en múltiples esferas sociales (esfera del trabajo, la familia o afectiva, del compromiso -político, militante- y la propia esfera escolar) y a través de las distintas modalidades con que se construyen percepciones y ajustes entre tales espacios (Dubar, 
1998, Passy, 2005). Esta literatura ha resaltado también el papel fundamental de los "accidentes biográficos" -o como Hughes (1981) llama los turning point-: momentos de reorientación biográfica y que pueden tener como elementos detonadores las crisis personales, los ciclos de vida (casamiento, nacimiento de un hijo, un reencuentro amoroso, envejecimiento), las experiencias de conflicto familiar o, inclusive, de desempleo o de discriminación racial, como es el caso específico de este estudio. Estos eventos y rupturas son constitutivos de las trayectorias y permiten reorientar la carrera y direccionar las inversiones profesionales y militantes (Willimez, 2004).

Por lo tanto, los estudios que se centran en la relación entre compromiso asociativo, formas de actuación profesional y usos del conocimiento especializado presentan un desafío teórico y metodológico de aprehensión relacional del ejercicio profesional y de las condiciones y lógicas del compromiso político. En los últimos años se han producido numerosos trabajos nacionales e internacionales desde las ciencias sociales que tiene por objetivo poner en evidencia tales vínculos. Uno de los aspectos destacados en este conjunto de análisis es la confrontación entre los abordajes centrados en la formación universitaria como condición sine qua non para la inserción en los diversos espacios de actuación profesional, y aquellos que destacan las diversas modalidades de uso de las cualificaciones, y relaciones profesionales en juego en las formas, también diversificadas de actuación e inserción en la militancia y en el compromiso con las organizaciones de la sociedad civil (Coradini, 2001; Dulong, 1996; Willimez, 2004).

\section{El surgimiento de una abogacía comprometida: trabajo profesional y movilización política}

La relación entre actuación profesional y compromiso militante, en el caso específico del derecho, ha sido abordada por un conjunto de estudios que resaltan el surgimiento del activismo jurídico como resultado de la articulación entre trabajo jurídico y movilización política. La importación de causas colectivas al espacio jurídico y la emergencia de "nuevos" usos del derecho han sido presentadas como un fenómeno reciente. La movilización de los abogados apareció de forma más explícita sobre el ámbito del derecho laboral y el ejercicio de la abogacía sobre el marco de los sindicatos de trabajadores, bajo el contexto de la década de 1970, principalmente en Francia. En el caso de Estados Unidos, en ese mismo periodo, se puede observar la presencia de abogados que defendían a los excluidos del establishment. En América Latina la lucha de los abogados se manifiesta en la defensa de los presos políticos, sobre todo en el periodo de proscripción política impuesto durante las dictaduras militares. Así, las diversas causas sociales que movilizaron a los abogados en diferentes periodos dependen del contexto y de las situaciones nacionales específicas. 
La forma que asumió la defensa de los abogados también contribuyó, en algunos casos, a influir en la dinámica de los estudios sobre activismo jurídico en estas diferentes situaciones nacionales. En el caso de Francia, como muestra Willemez (2003), se destacan los estudios sobre los abogados que luchan en defensa de los trabajadores, especialmente en el ámbito de los accidentes de trabajo y en acciones contra la discriminación. En Estados Unidos se ha relacionado este fenómeno con el surgimiento de los cause lawyer (abogados de causas), como nos muestran Austin Sarat y Stuart Scheingold (1998). Los estudios sobre los cause lawyer suscitaron numerosas investigaciones de campo, entre las cuales se incluyen las referidas a los juristas americanos que defienden la igualdad de salarios entre hombres y mujeres, los animales o la abolición de la pena de muerte.

Los estudios sobre América Latina se centran en la importancia que desempeñaron las redes internacionales en la transnacionalización de las causas en derechos humanos. La defensa de presos políticos está asociada a la vinculación de los abogados locales con redes internacionales de derechos humanos, que se hizo visible en la denuncia de torturas y detenciones en los foros internacionales. De este modo se destacan, por un lado, las redes formales constituidas a partir de comisiones nacionales e internacionales y, por otro, las redes informales de cooperación entre abogados. Como Meili (1998) llama la atención para el caso de Brasil, en el periodo de dictadura militar hubo una fuerte disminución de las redes formales constituidas por las asociaciones profesionales (tales como la Orden de los Abogados) y una ampliación de las redes vinculadas a la defensa de las causas de los movimientos sociales. Una de las características que ha sido presentada al respecto está asociada con la asesoría que los abogados han prestado a los movimientos sociales. Como la literatura sobre el tema resalta, las asesorías técnicas actualmente representan una de las posibilidades de ampliar la actuación profesional, contribuyendo hacia la "expansión horizontal" de la profesión, es decir, la combinación entre ejercicio profesional y otras formas de actuación (Coradini, 2006).

Sin embargo, otros enfoques han resaltado la necesidad de examinar la relación entre espacio jurídico y movilización colectiva de forma más crítica, lo cual implica considerar tanto los cambios en el espacio del derecho y el papel de los agentes en la traducción de las causas militantes en causas profesionales, como en las estrategias de apropiación de los movimientos sociales del espacio jurídico (Israël, 2001). Como muestran Gaïti e Israël (2003), la ampliación de las esferas de acción jurídica emerge asociada a la ampliación del militantismo experto. La reivindicación de derechos solicitada por diferentes grupos -en defensa de los homosexuales, de las mujeres o los animales- y el pasaje de esas reivindicaciones al ámbito del derecho -bajo la forma de consejos, comisiones y redes formales o informales- contribuye al desarrollo de las causas. En resumen, tales estudios se han centrado en la forma en que los abogados concilian la práctica profesional y el compromiso militante, orientando la investigación a los modos de definición de los usos militantes del derecho y la manera cómo los profesionales ejercen el papel de traductores de los problemas sociales hacia la esfera jurídica. 
En el caso de América Latina, y especialmente de Brasil, el movimiento de los derechos humanos adquirió proporciones destacadas a raíz de los movimientos políticos de contestación de las dictaduras militares que tuvieron lugar a partir de la década de 1970. No obstante, las modalidades de compromiso de los abogados en causas colectivas se modificaron substancialmente durante la década de 1990 en función de la ampliación de los movimientos sociales ocurrida durante ese periodo. Es entonces que los abogados invierten en la traducción de las problemáticas construidas en el ámbito de los movimientos sociales al universo del derecho. El estudio de Engelman (2006) sobre el conjunto de las demandas interpuestas ante la Corte Interamericana de Derechos Humanos entre 1970-2005 muestra que entre las causas que predominaron en Brasil en el periodo de 1988-2005, instituidas como de derechos humanos, están: derechos ambientales, derechos indígenas y los derechos de los "Sin-tierra". La mayor incidencia de las causas colectivas es en las regiones norte y centro-oeste, donde se destacan las causas referidas a derecho ambiental. Las causas raciales, por su parte, no aparecen asociadas a demandas de derechos humanos dado que constituyen un fenómeno reciente en el ámbito del derecho brasileño.

\section{La construcción e institucionalización de una causa: el derecho racial}

La defensa de los derechos raciales y la lucha contra la "discriminación por color" adquiere forma en el derecho brasileño a partir de la Constitución de 1988, la cual instituye la práctica del racismo como un crimen sujeto a pena de prisión, sin fianza e imprescriptible. Sin embargo, ya desde 1951, con la Ley Afonso Arinos (ley 1.390/51), la legislación brasileña definía los primeros conceptos de racismo, aunque no lo calificaba como crimen sino como contravención penal, y por lo tanto, considerada un acto delictivo de menor gravedad que el crimen. Esta ley incluyó, entre las contravenciones penales, la práctica de actos resultantes de prejuicios raciales o de color, y fue reformulada por la Ley Caó en 1985 (ley 7.437), la cual mantuvo al racismo como contravención penal, con pena simple y multa. La ley Caó incluía también la discriminación vinculada al sexo y al estado civil.

De modo que, aunque se iniciaron cambios en la década de 1950, sólo adquirieron importancia a partir de la Constitución de 1988, la cual contribuyó a la redefinición institucional del país y creó las condiciones de posibilidad del uso del espacio jurídico y de nuevas formas de movilización en la arena judicial. Fue sobre todo a partir de la década de 1980, un periodo de intensa actuación del movimiento negro, que el Estado fue obligado a manifestarse contra el racismo de forma constitucional. Fue durante el proceso de reforma constituyente que los líderes del movimiento negro se manifestaron y ganaron visibilidad. Ese pe-

3 Movimiento social brasileño que tiene como objetivo la implantación de la Reforma Agraria en Brasil. 
riodo también representa para el movimiento negro un momento de unificación de la militancia, que se había iniciado en la década de 1970 con la creación del "Movimiento Negro Unificado" y que tenía por objetivos denunciar todo tipo de racismo y organizar a la comunidad negra. En las décadas de 1980 y 1990 se conquistaron dos de las banderas de lucha del movimiento negro; por un lado la criminalización del racismo y, por otro, la reglamentación de las tierras de los "remanecientes de quilombo"4. El reconocimiento otorgado por el Estado durante la Constituyente representó otra conquista del movimiento negro, que se tradujo en el otorgamiento de garantías para la ocupación comunitaria de tierras y la obtención de títulos de propiedad. En este proceso desempeñaron un papel fundamental las luchas internacionales anti-racistas, sobre todo en Estados Unidos y Europa. La lucha por los derechos civiles y contra la segregación racial en Estados Unidos durante la década de 1970 y la lucha contra la xenofobia en los países europeos marcaron el cuadro de una nueva agenda política contra el racismo y la discriminación racial en los países de América Latina (Nogueira, 2004). Sin embargo, aun cuando la Constitución de 1988 transformó al racismo en crimen, sólo fue reglamentado y pasó a ser incluido dentro del código penal con la sanción de la ley 9.459 del 13 de mayo de 1997.

De este modo, el surgimiento del movimiento negro y las modificaciones legales que resultaron de su actuación, permitieron la emergencia de nuevos derechos y, con ello, la posibilidad de una actuación comprometida en el ámbito de la profesión. Según la expresión de Sidney Tarrow (1998), son las "estructuras de oportunidades políticas" las que permiten a los actores de los movimientos sociales movilizar la ley a favor de determinadas causas. En este sentido, podemos afirmar que el momento de apertura política y de redemocratización de la política brasileña, así como la organización del proceso constituyente que comenzó en la década de 1980, crearon las condiciones para la emergencia de nuevos actores y de nuevas formas de activismo jurídico en la política nacional. Entre estos nuevos actores están los movimientos sociales que contaron tanto con cuadros militantes provenientes de diferentes formaciones universitarias, como con abogados que se sintieron autorizados a movilizar la ley a favor de las causas que emprendían.

Es importante destacar que al comienzo de este proceso la actuación de los abogados en defensa de los derechos de los negros se daba de forma aislada e individual, destacándose la creación de algunas asociaciones y programas como

4 La expresión "remaneciente de quilombo" es objeto de un conjunto de estudios y debates que se produjeron en las ciencias sociales brasileñas a fin de buscar una definición adecuada para el término. Según Arruti (2001) la categoría "remaneciente de quilombo" es de naturaleza jurídica e instituye una nueva figura de derecho, sustentada en una categoría histórica que es la del "quilombo". Con la Constitución de 1988 el término "quilombo" asumió un nuevo significado, ya no más asociado a la definición histórica de grupos formados por esclavos que escaparon de esta condición. El término es actualmente usado para referirse a la situación de segmentos negros en diferentes regiones de Brasil que poseen tierras resultantes de la compra de esclavos liberados o, aun, resultantes de la ocupación de tierras abandonadas por parte de ex esclavos, o de la ocupación de tierras donadas a esclavos o adquiridas por esclavos organizados en quilombos. Una discusión más profunda sobre la cuestión se puede encontrar en Arruti (2001; 1997). 
por ejemplo, la "Associação Nacional dos Advogados Afro-Descendentes" y el "Programa SOS Racismo" propuesto por el gobierno federal. También surgieron en ese periodo estudios profesionales especializados en estas causas, como los estudios del "Instituto de Advogacia Ambiental e Racial". Todas esas instituciones no sólo contribuyeron a la divulgación de estas causas por medio de seminarios, encuentros y manifestaciones, sino que se consolidaron como importantes espacios de actuación profesional a través de los cuales integrar trabajo profesional y compromiso militante.

La "Associação dos Advogados Afro-Descendentes" (ANAAD) fue fundada en el año 2000. Se presenta a sí misma como una entidad sin fines de lucro cuyos objetivos son los de promover la igualdad racial y contribuir a una mayor inserción de los profesionales del derecho afro-descendientes que enfrentan dificultades para alcanzar mayores y mejores espacios en el mercado de trabajo. Según su presidente, "El racismo también está presente en el mercado de trabajo. Nosotros enfrentamos mil dificultades y por eso todavía somos pocos los que accedemos a carreras jurídicas como la Magistratura y el Ministerio Público". Entre las actividades desarrolladas por la organización se destaca el Curso Preparatorio para el Acceso a Carreras Jurídicas dictado por los abogados afro-descendientes y el Primer Seminario de Promoción de la Igualdad Racial que reunió a profesionales del derecho, políticos y miembros del movimiento negro. Creada en Salvador (Bahía), la ANAAD ya tiene sede en cuatro estados brasileños. Su actividad contribuyó a ampliar las formas de actuación profesional permitiendo que, recientemente, la Ordem dos Advogados do Brasil (OAB) crease la Comissão Nacional de Promoção da Igualdade. La presidencia de dicha comisión quedó a cargo de la presidenta de la ANAAD, la abogada Sílvia Cerqueira, quien, además de poseer una formación específica en el área de derechos humanos, posee una larga historia de militancia y de participación en otras asociaciones profesionales, tales como la Comissão de Proteção dos Direitos das Mulheres de la sucursal de la OAB del estado de Bahía y la "Associação Brasileira de Mulheres de Carreira Jurídica", desempeñándose allí como consejera nacional.

Al agradecer la invitación para presidir la "Comissão Nacional de Promoção da Igualdade", la abogada destacó "el coraje de haberse constituido una comisión de tal magnitud y de colocar como presidente a una mujer negra, nordestina y pobre". Los tres calificativos utilizados (negra, nordestina y pobre) remontan a tres historias de discriminación que pueden ser observados en su historia personal. Para esta abogada, el derecho desempeña un papel fundamental en el proceso de reducción de las desigualdades, pues, según ella,

vivimos en un país impregnado de prejuicios y discriminaciones, ya sea visibles o invisibles, que daña el tejido social de la comunidad brasileña. Por eso, nos toca a nosotros la responsabilidad, en cuanto defensores de la Constitución y del Estado democrático de Derecho, de los derechos humanos y de la justicia social, avanzar hacia la promoción de los derechos y la dignidad 
de todas las personas que integran el segmento históricamente, o no, discriminado de la sociedad brasilera (Ordem dos Advogados do Brasil, OAB).

De forma semejante, el "Instituto do Advogacia Racial e Ambiental" (IARA), creado en el año 2003 en el estado de Río de Janeiro se define como una entidad jurídica sin fines de lucro y con intervención en las áreas de Derecho Racial y Ambiental. El instituto se centra en:

la promoción y defensa de los derechos de la población afro-brasileña, tanto en el espacio urbano -estando sus acciones predominantemente dirigidas a las relaciones raciales en la educación escolar, en el mercado de trabajo y en las acciones afirmativas- como en las comunidades remanecientes de quilombo, en las comunidades negras rurales y también apoyando jurídicamente a migrantes clandestinos africanos (ver www.iara.org.br/ index.html).

Esta entidad creó el "Observatório do Advogacia Racial", que cuenta con el apoyo y el trabajo conjunto de diversas entidades del movimiento negro de Río de Janeiro. Una de sus principales áreas de actuación es la representación legal de organizaciones vinculadas al movimiento negro, interviniendo en acciones vinculadas a la defensa de "causas raciales" tales como la discriminación y la desigualdad racial en el ámbito del trabajo, abogando por el cumplimento de los cupos raciales y la obligación legal de impartir cursos sobre la historia de África en todos los niveles de la educación básica. Humberto Adami, su presidente, dirigió anteriormente otras entidades como la "Federação Nacional dos Advogados", fue miembro del Consejo Superior de la Facultad Zumbi dos Palmares/Afrobras, presidente del "Sindicato dos Advogados" del Estado de Río de Janeiro, director de la "Associação dos Advogados do Banco do Brasil" y miembro de la "Associação Brasileira dos Advogados Ambientalistas". Recibió varios premios por su actuación contra la discriminación racial en el Estado de Río de Janeiro como el Zumbi dos Palmares y el Raça Negra da ONG AFrOBRAS. En su perspectiva, es preciso promover una "abogacía de combate":

La abogacía de combate defiende el interés de los que están excluidos. Cuando estuve en Estados Unidos, en un programa del consulado norteamericano, los activistas negros de allá me dijeron lo siguiente: Nosotros enjuiciamos todo y todo el tiempo. El Brasil no aprendió aún a hacer eso (...) La abogacía de combate pretende ser la voz de los que quedaron afuera. Pretende llevar las demandas de nuestro campo a los tribunales todo el tiempo y desde el ángulo de la Constitución. Con esto se pueden abarcar las más diversas ramas y principalmente también para terminar de una vez con ese estigma que se creó en la sociología, en la antropología y en la ciencia política, de que el derecho va a trasmano de las transformaciones sociales. En verdad, todo lo que estamos haciendo, no sólo los abo- 
gados sino lo que el IARA está haciendo en conjunto con otras entidades del Movimiento Negro, nunca precisó de una resolución, de una medida provisoria o de una ley. Lo que nosotros usamos todo el tiempo fue el instrumental jurídico que ya está a disposición de los brasileños y de los tribunales (Adami, S/F).

Este relato evidencia la forma en que los abogados contribuyen a la construcción y defensa de causas políticas en la esfera del derecho. La "abogacía de combate" promueve la utilización del instrumental jurídico para asegurar los derechos y la ciudadanía de la población negra:

Creo que tenemos buenas leyes pero lo que falta es una mejor aplicación en el campo práctico. En relación con esto hemos buscado enjuiciar un gran número de acciones buscando un pronunciamiento del Poder Judicial sobre una gran cantidad de casos. Sólo a partir del uso continuado de las leyes, a través de las decisiones de varios jueces, es que tendremos lo que en Derecho se llama jurisprudencia (...) Respecto a las leyes, cito especialmente a la Ley CAO, que está celebrando los 15 años de existencia este año. Sin embargo, veo que es en el campo del Derecho Civil el mejor lugar para ejercer una ofensiva anti-racial a partir de aplicar pesadas condenas indemnizatorias, tales que cohíban las prácticas de racismo (Adami, S/F).

Se puede observar aquí cómo la profesión es colocada al servicio de una causa que articula la defensa de grupos que presentan una larga historia de discriminación y la reivindicación de derechos que pasan por el acceso y el uso de la justicia. La actividad profesional del derecho y la esfera jurídica se convierten entonces en recursos importantes en la defensa de causas marcadas política y socialmente, contribuyendo, de este modo, a definir la posición de estos profesionales en el campo de poder. Otra experiencia que puede ser mencionada es el caso del programa "SOS Racismo", implementado a comienzos del 2000 mediante una acción conjunta entre ONGs y la Secretaría de Derechos Humanos de la Nación con el objetivo de ofrecer a las víctimas de racismo y de discriminación étnicoracial un servicio de asesoría jurídica y de atención psicosocial. Este programa, basado en experiencias de otras naciones que se orientaron hacia la protección de otros grupos sociales como los inmigrantes, por ejemplo, para el caso de Francia (Juhem:1998), se definió en Brasil como un programa de combate a la discriminación por color y de apoyo a las víctimas de racismo.

Entre las diversas instituciones y entidades que también recibieron apoyo del gobierno se puede citar la ONG "Maria Mulher", que agrupa a mujeres negras afiliadas al movimiento feminista y al movimiento negro con sede en Rio Grande do Sul. Desde 2001 esta entidad promueve el programa "sos Racismo" que contó inicialmente con apoyo y financiamiento de la Secretaría de Derechos Humanos, apoyo que está interrumpido actualmente por encontrarse desactivado este or- 
ganismo de gobierno. A pesar de ello, la organización continúa con el programa ya que cuenta con otras fuentes de financiamiento (Fundo Brasil do Direitos Humanos, etc.). Esta continuidad resultó en un importante reconocimiento: en el año 2005 el programa recibió el VIII Premio de Derechos Humanos de Rio Grande do Sul.

En lo que respecta a los objetivos del programa "Sos Racismo", una de las abogadas de la organización "Maria Mulher" y representante del programa me explicaba en estos términos las razones de la propuesta:

Las cuestiones raciales eran tan sólo discutidas en la esfera teórica, en la academia. En aquella época la cuestión racial era combatida, debatida, discutida, pero el Fulano de la esquina continuaba siendo discriminado. Esta es una característica de las mujeres negras, el hecho de trabajar directamente con las bases. Entonces nosotras también discutimos la teoría, nosotras también estamos en la academia, pero también tenemos que mirar al Fulano que está siendo discriminado y ayudarlo a superar esa barrera. Ésta ya era una idea de Maria Mulher, cuando surgió el programa promovido por el gobierno sos Racismo ${ }^{5}$.

Desde esta perspectiva es preciso trascender la barrera de la academia y llegar a las víctimas de la discriminación racial. El conocimiento "teórico" es visto como un conocimiento que, para alcanzar a las víctimas, debe ser puesto en práctica con el fin de ayudarlas a superar las condiciones a las cuales están expuestas. Para ello cuenta con la participación de diferentes saberes especializados, como asistentes sociales, psicólogos y abogados, promoviendo respectivamente tres tipos de servicios: servicio social, atención psicológica y asesoría jurídica. En lo que respecta al primero, se busca fortalecer la capacitación de los afrodescendientes en el combate al racismo fomentando la demanda de sus derechos. Respecto al segundo servicio, el programa ofrece apoyo psicológico a las víctimas que enfrentan violencia racial, tanto por medio de una atención individual como a través de talleres donde se reflexiona sobre el racismo. Por último, el servicio de asesoría jurídica también tiene como meta posibilitar el acceso a la justicia y asesorar a las víctimas sobre el proceso de denuncia, acompañándolas desde la fase inicial hasta la fase final de la sentencia judicial.

Una de las premisas principales del servicio de asesoría jurídica es la de llevar las causas de discriminación racial a la arena jurídica posibilitando con ello la aplicación de la legislación anti-racista y que el racismo pueda ser visto cada vez más como un crimen. A pesar de que el programa considera que la legislación no contempla la diversidad de formas de discriminación a las cuales están sometidos los negros, concibe al poder judicial como uno de los principales agentes en la defensa y protección de los derechos humanos. El programa, en su primer año de actuación (2001), conmemoró las 40 acciones iniciadas en la justicia por dis- 
criminación racial y con el paso de los años obtuvo triunfos reales en la esfera de justicia a través de la condena de los agresores. La abogada, también del equipo de SOS Racismo, sostiene que este resultado:

es realmente una de las victorias más importantes de toda la trayectoria del Programa. Estamos consiguiendo quebrar una barrera más, la sentencia de $1^{\text {er }}$ Grado. Pero aún tenemos muchas más barreras para derribar vinculadas al tema de la Discriminación Racial. El sos Racismo puede ser felicitado, ya que, a pesar de las dificultades, está alcanzando su objetivo (Fuente: www.mariamulher.org.br).

La utilización de la justicia se presenta en este caso como un substituto de la arena política tradicional y como un espacio de lucha política, constituyéndose en una importante herramienta para construir e imponer una causa.

Una de las principales cuestiones que se destacan en este trabajo es la emergencia de un militantismo experto sobre la cuestión racial vinculado directamente a la ampliación y la intensificación de la acción jurídica. La reivindicación de derechos por parte del movimiento negro y la intervención del derecho en la formulación de leyes contribuyen al desarrollo y emergencia de causas y a que los abogados se sientan autorizados a desempeñar el papel de intermediarios en la expresión del descontento social y de diversas reivindicaciones. Los grupos organizados de abogados también desempeñan un papel fundamental en lo que podríamos llamar -tomando prestada la expresión de Boltanski (1982)- el "trabajo de movilización" alrededor de problemáticas comunes. El desarrollo de actuaciones y espacios como éstos, que definen posiciones a ser ocupadas, contribuye a orientar las expectativas y proyectos vinculados al ejercicio de la profesión.

El análisis de estas iniciativas explicita una nueva configuración de las relaciones profesionales en el ámbito del "derecho racial". La nueva interacción entre derecho y acción política pone en evidencia lo que Bourdieu llamó la "fuerza del derecho" (Bourdieu, 1990). Tal como se analizó en otros casos (Israël, 2001), es posible identificar algunas de las dimensiones que caracterizan esta nueva configuración. La primera comprende los procesos de articulación de las historias personales de las víctimas a una larga experiencia de discriminación y prejuicio que se retrotrae al sufrimiento originado en la esclavitud. La discriminación racial es presentada como un fenómeno histórico de larga data que precisa ser reparado. La segunda dimensión refiere a la politización y consiste en utilizar el derecho para poner en evidencia la exclusión de la cual son víctimas sus representados, movilizando para ello un conjunto de herramientas propias del campo jurídico. La tercera dimensión remite al proceso de elaboración de estrategias para atender a las necesidades de este grupo promoviendo los esfuerzos colectivos y trabajando frecuentemente en conjunto con los movimientos sociales. La cuarta dimensión implica la judicialización de las causas raciales, o sea el hecho de poner en acción la esfera jurídica a fin de ampliar el 
espacio de defensa de una causa. Las cuestiones pasan a ser decididas en esta esfera por medio de la utilización de argumentos jurídicos, transformando un caso privado de discriminación en un problema público. En consecuencia, por medio de un conjunto de documentos y pruebas, es posible convertir la discriminación en una causa jurídica.

Como lo muestra Willimez (2003) en el caso de los abogados laboralistas, el trabajo de judicialización es también una actividad de politización ya que es preciso buscar en el testimonio la culpabilidad del acusado. Un ejemplo de esto puede encontrarse en el relato que presentaré a continuación, proveniente de una de las abogadas del programa sos Racismo en el que explica en qué consiste buscar la culpabilidad en el testimonio del acusado:

Cuando comencé a explicar cómo son las relaciones raciales en el cotidiano y lo que ocurre con el negro en la sociedad, allí comencé a tener éxito (...). La cuestión es saber plantear los interrogatorios, tanto hacia el acusado como a los testigos que trae la víctima (...). Principalmente los testigos que trae el acusado (...). Quien me va a decir si aquella persona pudo haber ofendido racialmente a otra es el propio acusado. Él siempre va a decir que no hizo aquello por lo cual está siendo acusado. Entonces comienza a decir que llamó al otro de esto, de aquello, pero que no lo quiso hacer porque hasta tiene un amigo negro. Ahí el amigo negro viene a dar su testimonio y cuando viene le preguntas: y bien, cél va mucho a tu casa? Uno percibe el grado de amistad y ve que no se tiene nada que ver con lo que la persona dijo (...). Hubo uno que dijo que llamó al otro apenas de "cachorro de carcará". Investigué qué era 'cachorro de carcará' y descubrí que es un animalito negro. Ella (la persona acusada) llamó al otro de animal negro. ¿Sabe?, y esto siempre es bueno aclararlo, el problema no es ser llamado de negro -yo soy una mujer negra- pero uno no puede ser ofendido por su condición de negro. La persona, cuando quiere ofender, quiere decir que no soy nada por la condición de mi piel. ¿Qué diablos! ${ }^{6}$

En conclusión, entre las condiciones que posibilitaron la constitución de esta causa se destacan el contexto de la redemocratización que creó las condiciones para institucionalizar la causa y para poder accionar constantemente en la esfera jurídica y la creación de una serie de asociaciones civiles que reivindicaron la defensa de las víctimas de la discriminación racial, en especial de los negros.

6 Entrevista concedida a la autora en noviembre de 2008. Según la abogada, la información de lo que era "carcará" fue fundamental para mostrarle al juez que se trataba de una ofensa de orden racial y discriminatoria. 


\section{Los abogados en defensa de la igualdad racial: compromiso militante, identidad étnica y actuación profesional}

El examen de la formación de un espacio de activismo jurídico debe también abordar de forma destacada las trayectorias sociales, políticas y profesionales de los actores que intervienen en la traducción al universo del derecho de las "causas raciales". Mediante este análisis es posible mostrar cuáles son las condiciones que posibilitan que un abogado consagre su vida profesional al activismo racial.

Al considerar sus trayectorias se pueden observar algunas características comunes, principalmente en lo que respecta a sus orígenes sociales modestos, a la ocupación principal de sus padres - de bajo grado de escolarización-, así como sus orígenes étnico-raciales, siendo todos ellos descendientes de negros. Pero a pesar de estas características comunes es posible identificar la existencia de dos modalidades distintas de asociación entre la expertise jurídica y el militantismo. La primera corresponde a un conjunto de casos donde el ingreso a la defensa de causas raciales ocurre de manera simultánea a la realización de la carrera de Derecho. Esto supone que antes de comenzar sus estudios estos abogados no tenían una experiencia previa de militancia. En tales casos, el ingreso al activismo y la asociación entre profesión y militancia resultan de las redes de relaciones adquiridas a través de la familia o del grupo de amigos. La segunda modalidad está constituida por el conjunto de abogados que ya poseían una experiencia previa en el movimiento negro o en otras formas de militancia en el momento de ingresar a la carrera profesional.

Existe en estas dos modalidades de asociación entre expertise jurídica y activismo no sólo una amalgama sino también una fuerte referencia a la identidad étnica y a las diferentes formas de racismo sufridas "en carne propia" por los propios abogados desde la infancia. Así, en el proceso de reconstrucción de su pasado y en la representación de sus orígenes sociales es posible percibir que la memoria asociada al prejuicio racial sufrido es accionada y reactivada por ambos grupos de profesionales como justificación de la defensa de la causa racial en el ámbito del derecho.

En lo que respecta a la primera modalidad, uno de los casos más representativos es el de la abogada que actualmente coordina el programa Sos Racismo. $\mathrm{Su}$ ingreso a dicho programa se hizo efectivo a través de una pasantía como estudiante y por tener la recomendación de su hermana quien, a su vez, conocía a la hija de una de las coordinadoras de la ONG "Maria Mulher". En ese momento, la ONG estaba buscando una abogada que fuese, al mismo tiempo, mujer y negra ya que, anteriormente, esta asociación integrada por mujeres negras había contado con un abogado negro y una mujer blanca. Su experiencia en esta ONG es considerada por la entrevistada como clave en su trayectoria posterior, ya que no sólo le permitió conocer una técnica de trabajo sino que se descubrió ella misma una Maria Mulher, esto es, una militante en la defensa de las víctimas de discriminación racial. Si bien cuando terminó su pasantía debió buscar otro trabajo 
(dactilógrafa) continuó participando de las actividades de la ONG hasta terminar su carrera pues, según ella misma relata, "fue atraída por la causa". Después de recibida, la ONG la invitó a participar del Programa ya desde su condición de abogada. En ese periodo la entrevistada había montando su propio estudio de abogacía en el área criminal y había comenzado a actuar simultáneamente en los dos espacios. En la organización Maria Mulher algunas de sus actividades fueron remuneradas, dependiendo del financiamiento del proyecto obtenido por la ONG. La entrevistada, además de coordinar el proyecto SOS Racismo, participa desde 2008 en el proyecto Sentinela dirigido a la defensa de los niños víctimas de abuso sexual.

En este caso se observa que aparecen asociadas varias formas de militantismo, como el dirigido al movimiento feminista y, específicamente, al de mujeres negras, y también el referido a la defensa de los derechos de la niñez y la juventud. Cabe resaltar también que como resultado de su actuación en la ONG "Maria Mulher", la entrevistada se inició en la militancia partidaria afiliándose al Partido dos Trabalhadores (PT) ya que fue coordinadora de la campaña a concejal de una de las directoras de la ONG. Aunque la entrevistada no poseía un pasado militante, sus orígenes sociales sí remiten a una experiencia familiar de participación política. Su madre, además de participar en numerosas ocasiones en la coordinación y dirección de asociaciones barriales y escolares, era afiliada al Partido Democrático Trabalhista (PDT).

$\mathrm{Su}$ actividad en la ONG influenció fuertemente en la orientación de su actuación profesional ya que en el ejercicio privado de la profesión rechaza defender ciertas causas, como, por ejemplo, a quienes están siendo acusados de racismo, de violencia hacia la mujer o de pedofilia. Por otra parte, su desempeño en la ONG le permitió ampliar sus opciones tanto en el ámbito profesional como militante. Como ejemplo se puede mencionar su participación como miembro de la comisión de evaluación para la selección de empleados elegidos por sistema de cupos de la Municipalidad de Porto Alegre y la asesoría jurídica prestada a otra ONG. Como ella definió en entrevista, su actuación en el sos Racismo le dio "visibilidad y prestigio", además de reconocimiento en el mercado profesional del derecho dentro del área de discriminación racial. La necesidad de usar el derecho en la defensa de las víctimas del racismo es esencial para esta abogada, ya que, según ella, es cada vez más urgente presentar a la discriminación racial como un crimen.

Su disposición a la "lucha contra el racismo" se vincula asimismo a una historia personal de discriminación vivida a lo largo de su vida. En la entrevista mencionó ocasiones vividas tanto en la infancia como en la vida adulta que se constituyeron en experiencias clave para despertar su interés por la lucha contra la discriminación. La primera sucedió en la escuela. Se trató de una clase de lengua dada por una maestra blanca cuando dos compañeras que estaban sentadas delante de ella intercambiaron notas mientras la miraban y luego, una de ellas, se le acercó y pasó la mano sobre su frente diciéndole a la otra: "¿Ves? No sale". En un gesto de bronca, ella se levantó de su asiento y tomó la nota de sus compañeras donde estaba escrito que ella era "negra como carbón y que era tan negra que el color no 
salía". Le entregó esa nota a la maestra quien expulsó a las niñas de la clase y les exigió que le pidiesen disculpas.

La segunda situación ocurrió cuando estaba cursando el primer semestre de la carrera de derecho en la facultad Ritter dos Reis. Fue entonces que se dio cuenta que de los 100 alumnos que entraron junto con ella, sólo 5 eran negros y todos bien mayores que ella. Según la abogada, esta situación representaba un fuerte indicador de que el negro cuando entra en la facultad no lo hace joven y que ella era una excepción entre las excepciones. Así pudo entender un poco más la alegría de su madre, de sus parientes y de sus vecinos cuando entró en la facultad. En los primeros días de clase el profesor le pidió a los alumnos que se organizaran en grupo. En esta situación pudo percibir nuevamente el racismo velado ya que los únicos que la invitaron a formar grupo fueron los otros estudiantes negros.

A pesar de lo afirmado hasta aquí, es importante destacar que el análisis de la relación entre actividad profesional y militancia plantea la difícil tarea de articular dos espacios sociales distintos que, muchas veces, no convergen necesariamente entre sí. Una de las dificultades presentada por la entrevistada remite al hecho de que su intensa militancia en la ONG la aleja, por un lado, del conocimiento técnico de su profesión y, por otro, del círculo de relaciones sociales al interior de su universo profesional. Esto significa que para este tipo de carrera es un hecho clave conseguir circular en los dos espacios al mismo tiempo, sin que el desarrollo de uno perjudique el desarrollo del otro. Para enfrentar esta situación esta abogada realiza actualmente una maestría en ciencias criminales ya que considera que es fundamental estar informada sobre los cambios técnicos en el derecho así como convivir más con los profesionales del área. El caso descrito hasta aquí muestra la primera modalidad de ingreso en el derecho racial. Se trata de una experiencia profesional que posibilita convertir su actuación en el derecho en una forma de activismo.

La segunda modalidad aparece ejemplificada en el caso del fundador de un estudio de abogacía especializado en la defensa de víctimas de injuria racial. Dicho abogado también fue uno de los primeros en integrar el equipo técnico del Programa sos Racismo a comienzos de los 2000. Su ingreso a dicho proyecto se produjo como consecuencia de su intensa participación en el movimiento negro y de su reconocimiento en el área del derecho racial a partir de su trabajo en su estudio profesional. Oriundo de una familia con escasos recursos económicos -su padre fue custodio de la lotería del estado de Rio Grande do Sul y su madre era ama de casa-, trabajó en su juventud como vendedor de verduras y también como cadete de oficina. Recibido en Derecho en la Universidad Federal de Rio Grande do Sul, sus principales referentes en la elección de dicha carrera fueron su padre, en primer lugar, debido a su identificación con la causa negra y a algunas personalidades negras, en segundo lugar, tales como Alceu Collares, también abogado y exgobernador del estado de Rio Grande do Sul y Carlos da Silva Santos, quien fue el primer negro elegido diputado estadual. Esto indica que al momento de ingresar a la carrera de derecho el entrevistado ya poseía una intensa militancia en la defensa de los negros, iniciada al integrar un grupo de teatro dedicado a 
la temática negra, llamado Teatro Experimental do Negro y continuada después en la Sociedad Floresta Aurora. Este último grupo desempeñó un papel fundamental en la vida de los negros de la ciudad de Porto Alegre. Fundada antes de la abolición de la esclavitud, nucleaba a toda la comunidad negra de la capital y se orientaba tanto a la organización de bailes, actos públicos y protestas como a la asistencia social de ese segmento de la población.

A partir de esta militancia y de los contactos que de ella resultaron en los años 70 el entrevistado fundó junto con otras figuras actualmente activas del movimiento negro el Grupo Palmares, en plena dictadura militar. Este grupo fue responsable en 1995 de la propuesta de cambio de fecha del día de la Conciencia Negra que se conmemoraba el 13 de mayo -fecha de la abolición de la esclavitud- para el 20 de noviembre, fecha que recuerda la muerte de Zumbi dos Palmares ${ }^{7}$. El grupo fue, además, uno de los precursores en los cambios que tuvieron lugar al interior del movimiento negro, que pasó a afirmarse como grupo étnico y adoptó una postura que colocaba en jaque conceptos estructurantes de la sociedad brasileña, como la democracia racial y la identidad y cultura nacional. También contribuyó a la emergencia del Movimiento Negro Unificado (MNU) a fines de la década de 1970.

A lo largo de este periodo el entrevistado actuó en varios frentes. A comienzos de la década de 1970 ganó un concurso como auxiliar de escribano en el Banco del Estado de Rio Grande do Sul, donde continuó trabajando hasta jubilarse. Dicha actividad le permitió concluir la carrera de derecho y desempeñar un conjunto de actividades, como mantener un estudio propio de abogacía. Durante esos años y en la década siguiente, simultáneamente a la intensa participación militante, se desempeñó como locutor deportivo y también como locutor y comentarista en los carnavales. Uno de sus objetivos era hacer que la cultura del carnaval fuese contada por los propios negros y no por los no negros, como comúnmente ocurría. Tal actividad le abrió muchas puertas en el área del derecho, lo que se tradujo en diversas invitaciones para actuar como consultor jurídico de varias escolas de samba, como "Os Imperadores do Samba" y también de clubes de fútbol.

$\mathrm{Su}$ reconocimiento en el área del derecho racial deviene, a fines de la década de 1990, de su actuación profesional y del éxito que obtuvo en algunas causas de discriminación, llegando a lograr las condenas de los acusados. Una de las condenas que consiguió en el área racial estaba asociada a una lesión corporal, aunque si bien para él se trataba de una causa racial, fue la lesión la que le permitió obtener la condena. Entre las causas que ganó y que le permitieron destacarse puede citarse la causa contra la Caixa Econômica Federal, condenada a pagar una multa por discriminación racial en el ámbito del trabajo. Su actuación en el área del derecho comprende, además, un intenso compromiso en la producción de definiciones jurídicas a través de la publicación de artículos y comentarios sobre

Zumbi dos Palmares (1655 - 1695), descendiente de esclavos africanos procedentes de Angola, es considerado en Brasil uno de los máximos símbolos de la resistencia negra contra la esclavitud (Nota de los Editores). 
derecho racial y la actuación en asociaciones profesionales como la Associação dos Advogados Criminalistas donde es vicepresidente, y en el comité de ética de la OAB.

Así, la disposición a la acción militante manifestada por sus compromisos anteriores es reconvertida en este modo particular de activismo que involucra el uso político y social de la práctica profesional. Como ya poseía una larga historia en el movimiento negro, su clientela también es resultado de su activismo militante. Por lo tanto, la propia formación de la clientela remite a la imbricación de dos espacios de actuación: el del militantismo y el de la actividad profesional.

Como resultado de este conjunto de actividades que le proporcionaron, al mismo tiempo, notoriedad profesional y militante, recibió varios premios destinados a personalidades negras en el estado de Rio Grande do Sul como los Troféu Zumbi y el Troféu Carlos Santos de la Cámara de Concejales, entre otros. Esto pone en evidencia cómo el compromiso militante puede contribuir al éxito profesional, permitiendo la acumulación de capital social y simbólico.

De la misma forma que en el caso de la abogada desarrollado anteriormente, este abogado también asocia la defensa de la cultura e identidad negra a la propia experiencia de discriminación. Una de ellas ocurrió en su infancia, más precisamente en la escuela, con motivo de la solicitud que hiciera su madre de tres becas de estudio para sus tres hijos. Como sólo consiguió dos becas, la escuela - particular y católica- aceptó inscribir a los tres hijos a condición que limpiaran los salones de clase. Según el relato de este abogado, a pesar de que en aquella época esta actividad representaba una diversión para ellos, se trataba en el fondo de una explotación de menores, niños y negros, ya que la dirección de la escuela no habría exigido tal tarea a los hijos de una familia blanca. Como una manera de protegerse de las prácticas racistas, él y sus hermanos formaron una red de apoyo y protección. Si alguien hacía alguna cosa contra uno de ellos, éste era defendido por los otros dos.

Los relatos muestran que la actuación de estos abogados y las modalidades que adoptan en la defensa de las víctimas de discriminación racial comprenden tanto el tratamiento jurídico de los casos y el uso de una expertise como la defensa militante de una causa que aparece asociada a una experiencia personal de discriminación. Así, ellos se definen a partir de un uso comprometido del derecho, reivindicando públicamente sus convicciones, principios y valores y haciendo de esto una forma de ejercer su profesión. Además, es a partir de la configuración de sus carreras militantes que sus acciones profesionales toman sentido. La vinculación entre esas esferas profesional y militante adquiere un sentido específico para estos abogados, para quienes estas esferas están asociadas a la propia condición social e histórica que ocupan dentro de la sociedad brasileña y a las experiencias pasadas de discriminación. El derecho aparece entonces como una manera de responder a esta situación. De este modo, la actuación político-profesional de estos abogados permite dar un sentido a su trayectoria pasada produciendo una continuidad entre esos dos espacios distintos de actuación. Las trayectorias profesionales son constituidas entonces a partir de la reconstrucción del pasado que 
permite revelar visiones de sí y del mundo remitiendo a diversas esferas sociales y formas de identidad (Dubar y Tripier, 1998). Así, los ajustes y las percepciones hechas por estos abogados entre sus experiencias personales de discriminación y su actuación profesional permiten comprender los principios de identificación y las concepciones de profesión en juego.

\section{Conclusión}

El análisis de los abogados que se dedican a la tarea de traducir las "causas raciales" al derecho ofrece un campo de estudio particularmente fecundo para problematizar los usos políticos y militantes de la profesión. En esa línea, este texto buscó poner en evidencia cómo el derecho se puede convertir en un modo de acción y legitimación de causas políticas a partir del estudio de las concepciones políticas y profesionales y de las trayectorias de sus actores.

Una de las principales cuestiones que se destacaron en este trabajo es aquella relativa a las condiciones sociales que hicieron posible la defensa de la cuestión racial en el ámbito del derecho brasileño. Entre ellas sobresale el contexto de apertura política y de redemocratización en Brasil, lo cual posibilitó la institucionalización de la causa racial y la constante puesta en acción de la esfera jurídica, permitiendo la creación de un conjunto de asociaciones civiles que alzaron la bandera de la defensa de las víctimas de discriminación racial. Por otro lado, el estudio pretende mostrar -a partir de la investigación de las trayectorias sociales, políticas y profesionales de algunos abogados dedicados a la defensa de los derechos raciales-, cómo los principios de identificación étnico-raciales y la experiencia militante son fundamentales para conformar determinadas concepciones profesionales y usos del derecho.

\section{Bibliografía}

ARruti, José Maurício. 2001. "Comunidade remanescente de quilombos". Tempo e Presença 23 (319): 25-29.

ARruTI, José MAURÍCIO. 1997. "A emergência dos "Remanescentes": notas para o diálogo entre indígenas e quilombolas". Mana Estudos de Antropologia Social 3 (2): 7-38.

ADAmi, HumberTo. entrevista página web Irohim: http://irohin.org.br/onl/new. php?sec $=$ entrevista\&id $=520$

BolTANSKI, LuC. 1982. Les Cadres. Paris: Les Éditions de Minuit.

BOURDiEU, PIERRE; BOLTANSKI, LUC. 1975. "Lê titre et lê poste: rapports entre lê système de production et lê système de reproduction". Actes de la Recherche en Sciences Sociales 2: 95-107.

CANÊDO, LetíCiA BiCAlHo. 2002. "Gestão Familiar da escola e aprendizagem das habilidades para o ofício da política”. En Ana Maria F. Almeida e Maria Alice Nogueira (orgs.), A Escolarização das Elites: um panorama internacional da pesquisa. Petrópolis, RJ: Vozes, 76-100. 
Los Derechos Humanos se conquistan en la lucha...

Coradini, OdACI LuIs. 1997. "Grandes Famílias e "Elite Profissional" na Medicina no Brasil”. História, Ciências, Saúde - Manguinhos, III (3): 425-466.

CORADINI, ODACI LUIS. 2001. Em nome de quem? Recursos sociais no recrutamento de elites politicas. Rio de Janeiro: Relume Dumará.

CORADINI, ODACI LUIS. 2002. "Escolarização, Militantismo e Mecanismos de "Participação" Política". En Beatriz Heredia, Carla Teixeira, Irlys Barreira (orgs.), Como se Fazem Eleições no Brasil. Rio de Janeiro: Relume-Dumará.

Coradini, Odaci Luis. 2006. "Relações Profissionais e Disputas Eleitorais". En Cesar Barreira, Moacir Palmeira, Politica no Brasil. Visões de Antropólogos. Rio de Janeiro: Relume Dumará, 267-297.

Dogan, Michel. 1999. "Les Professions Propices à la Carrière Politique; osmoses, filières et vivieres”. En Michel Offerlé (dir.), La Profession Politique: XIXe. Siècles. Paris: Belin, 171-200.

Dubar, Claude. 1998. La Socialisation. Paris: Armand Colin.

Dubar, Claude; Tripier, Pierre.1998. Sociologie des Professions. Paris: Armand Colin.

Dulong, DelPhine. 1996. "Quand l'économie devient politique. La conversion de la compétence économique en compétence politique sous la Ve République". Politix 9 (35): 109-135.

ENGELMAN, FABIANO. 2006. "Internacionalização e Ativismo Judicial: as causas coletivas". Lua Nova, São Paulo 69: 123-146.

GAÏTI, BRIGITTE; ISRAËL, LIONOR. 2003. "Sur l'engagement du droit dans la construction des causes". Politix 16 (62): 17 - 30.

GAXIE, DANIEL. 2005. "Rétributions du Militantisme et paradoxes de l'action collective". Swiss Political Science Review 11 (1): 157-188.

GAXIE, DANIEL ; OfFerlé, Michel. 1985. "Les Militants Syndicaux et Associatifs au Pouvoir? Capital Social Collectif et Carrière Politique”. En Pierre Birnbaum (dir.), Les Élites Socialistes au Pouvir - 1980-1985. Paris: Press Universitaires de France, 105-138.

Hughes, Everet. 1981. Men and Their Work. Wesport Greenwood: Press Reprint.

ISRAËL, LIORA. 2001. "Usages militants du droit dans l'arène judiciaire: le cause lawyering”. Droit et Société 49 : 793-824.

JUHEM, PHILIPE. 1998. SOS-Racisme, histoire d'une mobilisation «apolitique». Contribution à une analyse des transformations des représentations politiques après 1981. Thèse en Science Politique, Université de Strasbourg.

LOUREIRO, MARIA RITA. 1997. Os Economistas no Governo. Rio de Janeiro: Fundação Getúlio Vargas.

Matonti, Frédérique; Poupeau, Franck. 2004. "Le Capital Militant". Actes de la Recherche en Sciences Sociales 155: 5-11.

MEILI, SARA. 1998. "Cause lawyers and social movements: a comparative perspective on democratic change in Argentina and Brazil". En Austin Sarat; Stuart Schingold (eds.), Cause Lawyering. Political Commitments and Professional Responsabilities. New York: Oxford University Press.

NogueirA, JoÃo CARLOS. 2004. "Movimento Negro: das denúncias de racismo à prática das políticas públicas". Política e Sociedade 5: 89-99

OfFERLÉ, MiCHEL. 1996. "Entrées en politique". Politix 9 (35): 3-5

Offerlé, Michel. 1999. "Professions et Profession Politique". En Michel Offerlé (dir.), La Profession Politique. Paris: Edition Belin, 7-36.

PASSY, FlorenCE. 2005. "Interactions Sociales et Imbrications des Sphères de Vie". En Olivier Fillieule (org.), Le Desengagement Militant. Paris: Edition Belin, 111-130.

Sarat, Austin; SCheingold, Stuart. 1998. Cause Lawyering. Political Commitments and Professional Responsibilities. New York, Oxford: Oxford University Press. 
SAWICKI, FRÉDÉRIC. 1999. "Classer les hommes politiques. Les usages des indicateurs de position sociale pour la compréhension de la professionnalisation politique." En Michel Offerlé (dir.), La Profession Politique. Paris: Edition Belin, 135-170.

TARrow, Sidney. 1998. Power in Movement: Social Movements and Contentious Politics. Cambridge: University Press.

WillemeZ, LAURENT. 2004. "Perseverare Diabolicum: l'engagement militant à l'épreuve du vieillissement social”, Lien Social et Politiques 51: 71-82. Montreal.

WiLLEMEZ, LAURENT. 2003. "Engagement professionnel et fidélités militantes. Les avocats travaillistes dans la defense judiciaire des salariés". Politix 16 (6): 145 - 164. 
